\title{
Exploitation and Utilization of Folk Sports in Physical Education's teaching in colleges and universities Ying $\mathrm{Li}^{1 \mathrm{a}}$ Wusi Yan ${ }^{2 \mathrm{~b}}$ \\ ${ }^{1,2}$ Pingxiang University, Jiangxi 337055, China 3559020645@qq.com, byanwusi@163.com
}

Key words: folk sports; physical education's teaching; development;

\begin{abstract}
The history of folk sports in China has a long history, and it has rich national traditional characteristics. It has strong inheritance value and educational significance. It is great significance to inherit folk sports culture and to promote college sports reform in college physical education teaching. How to develop and utilize local folk sports resources is a question that college sports workers and experts must correctly think about.
\end{abstract}

Folk sports has a long history, it is regarded as one of cultural treasures. How to inherit and develop the folk sports culture situation is more and more severe. The development and utilization of folk sports in college physical education can not only inherit and develop folk sports, but also enrich the content of physical education teaching in colleges and universities, but also promote the innovation and development of physical education teaching in colleges and universities.

\section{The concept of folk sports}

Folk sports, refers to people in the daily life in the production practice and gradually formed a pattern of long tradition, collective of traditional sports events. The folk sports is a branch of traditional sports, with a collective, inherited and model characteristics. As an important part of sports culture, It is regarded as one of the cultural treasures of folk sports. Both fitness, entertainment, education and other functions.

\section{The value of folk sports in colleges and universities}

\subsection{The importance significance of the transmission of folk sports culture}

there are 50 Kinds of local folk sports in Jiangxi Province, Many of these sports with regional characteristics and was folk cultural heritage. The development and utilization of the folk sports curriculum in colleges and universities is the practical action to save and preserve the local folk sports culture, and it is the performance of the traditional culture serving the modern education.

\subsection{It is beneficial to imparting traditional values}

Folk sports is an integral part of Chinese traditional culture, which contains a lot of educational content, such as values, ethics, aesthetics and people's behavior patterns. Physical education in colleges and universities must make full use of folk sports activities. To carry out moral education in a targeted manner is a way of education that college educators can not ignore.

\subsection{Promote the development of the reform of physical education in Colleges}

For a long time, because of the influence of athletic sports thought, the college syllabuses and textbooks are mostly sports. Although it has made remarkable achievements and great development in teaching practice for many years, it also exposes a lot of malpractice and defect. In order to change the situation of college physical education, China's colleges and universities launched a new round of physical education reform. We should introduce the folk sports into the physical education classroom of colleges and universities so as to enrich the contents of the national traditional sports curriculum and broaden the types and quantity of the students 'exercise projects. Meanwhile, it has far-reaching significance for improving college students' identity to folk sports. 


\section{The advantages of sports teaching of folk sports in Colleges and Universities}

\subsection{The support of the national policy is a solid guarantee for the development of folk} sports in Colleges and Universities

In recent years, the party and the state promulgated a series of reform documents and measures taken, we can easily see that the party and the state for the development of national sports and carry forward the great importance of national culture, which undoubtedly makes to the development of colleges and universities in Jiangxi province folk sports curriculum resources. The development and utilization of resources provides a rare opportunity to create a good political policy environment for the cause of the development of a guiding role.

\subsection{The advantages of folk sports provide a prerequisite for its development in colleges and universities}

Each of our nation has its own unique sports and their own characteristics, its content complex, different styles. These colorful folk sports resources for the school sports curriculum resources development provides a number of optional materials. It is easy to practice, no special venue, can be collective practice, more suitable for individuals; it is recreation and games, etc., highlight the physical activity of the technical, artistic and entertaining, simple style, fun; It can not only exercise, but also entertainment body and mind, regulating the psychological state, enhance the ideological and emotional exchanges between people. If the folk sports into the university, can greatly enrich the content of college sports teaching, but also can alleviate the shortage of funds for education, sports equipment, lack of space and other issues; but also enable students to improve physical and mental skills also get a pleasant experience, Which is conducive to shaping and improving the personality of college students; also conducive to the system of folk sports heritage and further standardized development.

3.3 The development of ordinary colleges and universities is conducive to the development of folk sports

Every nation in our country has its own unique sports and its own characteristics, its complicated content, different styles. These colorful folk sports resources for the school sports curriculum resources development provides a number of optional materials. Folk sports activities are simple and easy, no special venues, it can be recreational and games, etc., It highlights the skills of physical activity, art and entertainment, If the folk sports into the university, not only greatly enriched the content of physical education in colleges and universities, but also can alleviate the shortage of education funding, sports equipment, lack of space and other issues, so that students in physical, skills, psychological pleasure also get experience, so as to cultivate students' personality and the transmission of folk sports has a systematic nature, the development of the future will be more standardized.

\section{The countermeasures of developing folk sports resources in Colleges and Universities}

\subsection{Break the shackles of ideas, put the folk sports curriculum resources into physical education}

We must first change the concept of people to understand the folk sports function, nationality, practicality, necessity and importance of education and folk sports into the school. We should choose the folk sports resources with national characteristics, high exercise value, strong group, and significant humanistic education function to enter the PE classroom of colleges and universities in order to emancipate the mind and break through the traditional concept of school physical education, on the basis of the guiding outline.

\subsection{Increase the folk sports resources of the excavation and finishing}

Folk sports is an important part of Chinese traditional culture. Therefore, the excavation and arrangement of folk sports in our country, We must absorb its essence and refer to the outstanding achievements of modern sports on the integration of a new round of innovation in order to constantly update development. 


\subsection{Improve the enthusiasm of PE Teachers' Curriculum Resources Development}

Physical education teachers are important curriculum resources, the main force in the development and utilization of folk sports curriculum resources, and the guides and service providers for the development and utilization of folk sports curriculum resources. Therefore, the school should take effective measures to stimulate the physical education teachers to develop and use of sports and health curriculum resources initiative, give full play to the leading role of teachers in order to improve the quality of the development of curriculum resources.

\subsection{Expand cooperation channels with outside school}

The development and utilization of folk sports curriculum resources is a systematic project. We should strengthen the development and utilization of other human resources both inside and outside the school. We should also pay attention to the exchanges with folk artists and listen to their opinions and suggestions on the development of folk sports. In addition, PE teachers can learn from the folk artists to improve their skills, the formation of curriculum resources, the overall effect and advantages.

4.5 To increase the media publicity of folk sports, and enhance people's sense of identity of folk sports

Through the television, radio, network, newspapers, magazines and other forms of media, vigorously promote folk sports. Folk sports and the value of the full range of display, Zhang Yang folk sports unique entertainment, fitness and other characteristics, so that people in the subtle experience of folk sports culture rich and unique charm, the development of folk sports curriculum resources And the development of national traditional sports, inherit and carry forward our outstanding national culture, physical and mental health of students to form a lifelong idea of organic combination of sports.

\subsection{Improve the folk sports related mechanisms}

To formulate the development of folk sports measures to strengthen the folk sports curriculum resources in Jiangxi province mining, collation and practical theoretical research, compiled with Jiangxi local characteristics of folk sports teaching materials, while the functional departments should also establish a folk sports competition mechanism for its The promotion of Jiangxi universities to provide a broader approach.

\section{Acknowledgments:}

Draft date: 2016-10-1

Fund project: jiangxi province sports bureau scientific research subject 《The development of new rural construction under the local folk sports and study》, number: 2016035

\section{References}

[1] Zhu-li LI.On the development of folk sports curriculum resources in ordinary colleges and universities [J]. Western China Science and Technology, 2009 (26)

[2] Jun-qi Wang.Study on the Development of Folk Sports Resources in Jiangxi Colleges and Universities [J]. Sports Science Research, 2016 (3)

[3] Chu-tao Li, Wei Zhao. Folk sports culture value evolution rule research [J]. Journal of sports science, 2012 (6)

[4] Ruo-guang Wang, Man-hang Liu. Evolution of the function of folk sports modernization in China [J]. Journal of wuhan sports college, 201 (10)

[5] Jun Li. The western minority characteristics of folk sports in traditional festivals and culture value [J]. Journal of chengdu sports college, 2011 (1)

[6] Gang Li. The generating mechanism of folk sports culture [J]. Journal of shandong sports college, 2012 (6) 